\title{
Photovoltaic array maximum power point tracking via modified perturbation and observation algorithm
}

\author{
Bahaa Abdulkhaliq Numan, Amina Mahmoud Shakir, Anas Lateef Mahmood \\ Electronic and Communications Engineering Department, College of Engineering, Al-Nahrain University, Iraq
}

\begin{tabular}{l} 
Article Info \\
\hline Article history: \\
Received Dec 3, 2019 \\
Revised Feb 4, 2020 \\
Accepted May 19, 2020 \\
\hline
\end{tabular}

\section{Keywords:}

Buck DC to DC converter MPPT

P\&O Algorithm

Solar PV System

\begin{abstract}
One drawback of PVs is their low efficiency. As the PVs have a unique maximum Power Point for a specified irradiation level, there must be an effective method for extracting maximum power from the PV module to raise the efficiency. Conventional Perturbation and Observation $(\mathrm{P} \& \mathrm{O})$ is a simple algorithm for maximum power point tracking (MPPT) but it suffers from oscillation during steady state conditions and is deviated from the maximum power point during slow and rapid irradiation level change. This paper presents a modified $\mathrm{P} \& \mathrm{O}$ by adding variation in $\mathrm{PV}$ current as a third in addition to the voltage and power variation parameters. This new algorithm is capable of eliminating the MPPT deviation. To increase the perturbation speed, a double step is taken as the tracking is deviated from the MPP. The modified $\mathrm{P} \& \mathrm{O}$ algorithm is used to control the duty cycle of DC-DC buck converter. The simulation shows that the modified $\mathrm{P} \& \mathrm{O}$ is faster than the conventional. The power loss due to oscillation before attaining the steady state is less for modified P\&O. For slow irradiation level change (ramp up 600 to 1000 and ramp down 1000-800) W/m2, the modified P\&O shows less tracking diverge. As the irradiation level changes rapidly from 800 to 200 $\mathrm{W} / \mathrm{m} 2$, it's shown that the modified algorithm attains the steady state faster than the conventional $\mathrm{P} \& \mathrm{O}$ and the average efficiency increased by $4.34 \%$.
\end{abstract}

This is an open access article under the CC BY-SA license.

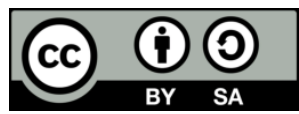

\section{Corresponding Author:}

Amina Mahmoud Shakir,

Electronics and Communications Department, College of Engineering

Al-Nahrain University,

Jadriyah, Baghdad, Iraq.

Email: amina_alkafaji@eng.nahrainuniv.edu.iq

\section{INTRODUCTION}

During the Industrial Revolution, the requirements for different forms of energy have increased dramatically, and the first choice for most applications is fossil fuels. This type of fuel is harmful and it had lead in searching for other sources of energy. Solar energy was the first of these sources, as it is a renewable energy, inexhaustible and clean energy. Investigations show that in one hour, the earth received energy from the sun enough to meet its needs for one year [1]. Photovoltaic (PV) system is considered one of the most important systems for the exploitation of solar energy and the most widespread. This type of system suffers from low efficiency compared with the other alternatives of sources as the energy generated by the photovoltaic module changes with the environmental conditions. Several methods can be used to increase the efficiency and performance of the PV module, Maximum Power Point Tracking (MPPT) is one of the common methods for increasing the efficiency of the PV module.

As the photovoltaic I-V characteristics are nonlinear and affected by environment condition, the P-V characteristics are also nonlinear and have a unique maximum point. MPPT methods seek for the unique 
maximum power point on the photovoltaic $\mathrm{P}-\mathrm{V}$ characteristics at a certain condition and hence maximize its efficiency.

Mainly there are two MPPT methods, direct and indirect, based on the implementation strategy. Direct methods, comprise the methods that use voltage and /or current measurement of the PV and its independent on prior knowledge of the PV characteristics while indirect methods are based on experimentally obtained databases. Many researchers have been reviewed these methods [2-6].

Viewing Intelligent methods such as an Artificial Neural Network (ANN) [7-9], Fuzzy Logic (FL) [10-12] and the Artificial Bee Colony (ABC) [13,14], show that they are mostly digital complex methods, requires a lot of calculations and expensive as they need to use powerful microcontrollers due to the enormous computational load. They have fast converged speed and the highest accuracy for tracking the MPP.

The most efficient direct methods are Incremental Conductance (INC) [15-16], Perturb and Observation (P\&O), Hill climbing (HC) [17-20]. These methods use algorithms for MPPT of the PVs. INC algorithm takes the incremental and momentary conductance as a base for construction. It senses PV current and voltage and use $\mathrm{dI} / \mathrm{dV}$ to calculate the indication of $\mathrm{dP} / \mathrm{dV}$ and adjusts the power converter duty cycle. $\mathrm{P} \& \mathrm{O}$ and $\mathrm{HC}$ measure the PV array voltage and current and calculate the power. It is mainly based on perturbation in the PV output voltage and observation of the result in power change of the PV array then compares this power with the previous power. These algorithms suffer from oscillation around the MPP during steady state and diverge from maximum point when rapid change of environmental conditions occurs which will lead to a higher power loss and hence low efficiency.

Among of these methods the P\&O which is the interest of this research are broadly utilized as it is a low cost, simple and easy to implement; besides it can be used practically in the microcontroller or Digital Signal Processing System [21]. To overcome the drawbacks of the conventional P\&O method a modification is made on the main algorithm in order to increase the array efficiency [22].

Many researchers have been focusing on the improvements of the conventional P\&O algorithm. Most researches presented a variable perturbation step size [23-26] others dealing with modified and adaptive fixed step size perturbation [27, 28]. A P\&O algorithm with fixed step must be chosen carefully, large step size causes a higher power loss, as the tracked maximum point is far from the real MPP. Using a small step size, lead to slow transient response of the system and will influence the overall performance the PV array [23].

This paper presents a comparison between conventional and modified $\mathrm{P} \& \mathrm{O}$ algorithm which is found in [27] to track the maximum power point of a PV system with fixed perturbation step and double perturbation step using Buck converter. The Buck converter is used here for its high efficiency and wide range of applications such as in self-regulated power supplies and point of load (POL) converters. P\&O technique that's used in PVs MPPT needs only two sensors, one for measuring the PV output voltage and the other for measuring the PV output current, the power is then can be calculated. The algorithms compare the $\mathrm{PV}$ voltage and the calculated power periodically with the voltage and power of the previous perturbation step and then control the duty cycle of the connected DC-DC converter to maximize the power output from the PV.

The modified P\&O algorithm is used to increase the PV array efficiency and overcome the drawbacks of the conventional $\mathrm{P} \& \mathrm{O}$ for MPPT at steady state as well as during rapid and slow irradiation level change. This is so done by taking variation in the PV current as an additional parameter to the conventional $\mathrm{P} \& \mathrm{O}$ which takes only the change in voltage and power. A double perturbation step size is taken as the tracking is deviated from the maximum point. This will reduce the oscillation around the MPP, reduce the losses and will lead to a faster response and hence increase the efficiency. A buck DC-DC converter which is a step down converter is utilized in order to match the output load to the PV array to fulfill the maximum power transfer.

\section{MPPT PHOTOVOLATIC SYSTEM STRUCTURE}

The main part of the solar system is the photovoltaic source, which generates DC electrical power when exposed photons. For transferring the maximum power from the PV to the load it is necessary to match the load impedance with the source impedance of the PV array. To do such a DC-DC converter is inserted between the PV array and the load. As the output power of the PV panel is variable according to the environmental conditions, the duty cycle of the converter must be controlled for maximum power transfer.

A form of maximum power point tracking is used for an accurate and fast result. The general block diagram of the MPPT PV system is shown in Figure 1. The main parts of the proposed system, is the PV array, the converter and the MPPT controller which is using the P\&O algorithm approach. 


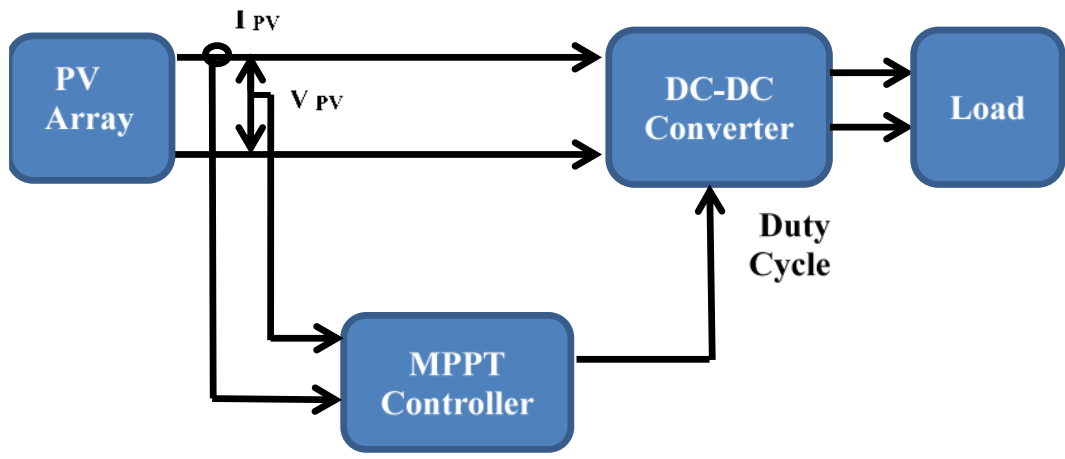

Figure 1. Block diagram of the proposed PV system with MPPT

\subsection{PV array modeling}

Modeling of PV arrays for different atmospheric conditions is an essential issue in designing the size of a PV system and its MPPT controllers. Different modeling has been presented in many researches [29, 30]. This research takes the single diode model shown in Figure 2 as an equivalent circuit for the PV array.

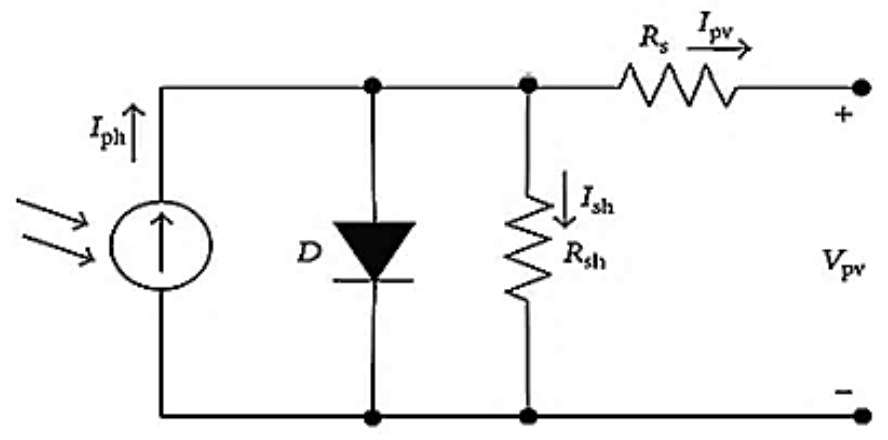

Figure 2. Single-diode PV model

The photovoltaic array consists of a series -parallel connected combination cells, therefore the PV output current $I_{p v}$ can be expressed as:

$$
I_{p v}=I_{p h}-I_{s}\left[\exp \left(\frac{V_{p v}+R_{S} I_{p v}}{N_{S} V_{T} a}\right)-1\right]-\frac{V_{p v}+R_{S}}{R_{p}}
$$

where, $I_{p h}$ is $\left(I_{p h \text {,cell }} N_{p}\right), I_{\mathrm{s}}$ is $\left(I_{\mathrm{s}, \text { cell }} N_{s}\right)$ are the PV and saturation currents of the array which is a combination of series and parallel connected cells, $N_{s}$ and $N_{p}$ respectively . $V_{T}=k T / q$ represents the thermal voltage of the PV cell, $q$ is the charge of the electron $\left(1.602^{*} 10^{-19} \mathrm{C}\right)$, k represents the Boltzmann constant $\left(1.3806503 .10^{-}\right.$ $\left.{ }^{23} \mathrm{~J} / \mathrm{K}\right), T$ is the temperature of the junction in Kelvin $(\mathrm{K}), a$ represents the diode ideality constant $(1<a<$ 5) and $R_{s}\left[r_{s}(\mathrm{Ns} / \mathrm{Np})\right]$ and $R_{p}\left[r_{p}\left(N_{s} / N_{p}\right)\right]$ gives the equivalent series resistance and equivalent parallel resistance of the module respectively, as $r_{s}$ and $r_{p}$ are the PV cell series and parallel resistance.

The (1) is nonlinear and shows that the I-V characteristics of the PV array depend on the internal passive parameters of the device $\left(R_{s}, R_{p}\right)$. It is also depending on the solar insolation (irradiation) level and temperature. The change of irradiance and temperature has an effect of the PV array current and voltage as given in the following equations:

$$
\begin{aligned}
I_{p h} & =\left[I_{p h, n}+K_{i}\left(T-T_{n}\right)\right] \frac{G}{G_{n}} \\
V_{o c} & =\left[V_{o c, n}+K_{v}\left(T-T_{n}\right)\right]
\end{aligned}
$$


Where the subscript $n$ represents the nominal operating condition (usually taken as $T_{n}=298 \mathrm{~K}$ and $G_{n}=1 \mathrm{~kW} / \mathrm{m}^{2}$ ), $\mathrm{Ki}$ and $K_{v}$ are the short circuit current/temperature coefficient and the open-circuit voltage/temperature coefficients of solar cell respectively.

From the I-V and P-V characteristics for different irradiation which are shown in Figures 3 (a and b) respectively, it is clear that for every level of irradiation there is a unique point where the entire system is able to work with maximum efficiency. This point is the maximum power point (MPP).

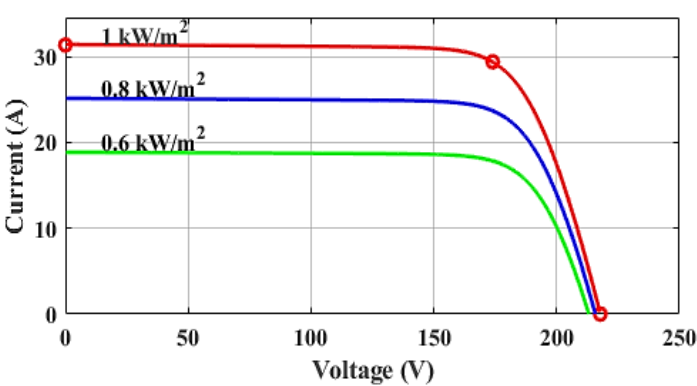

(a)

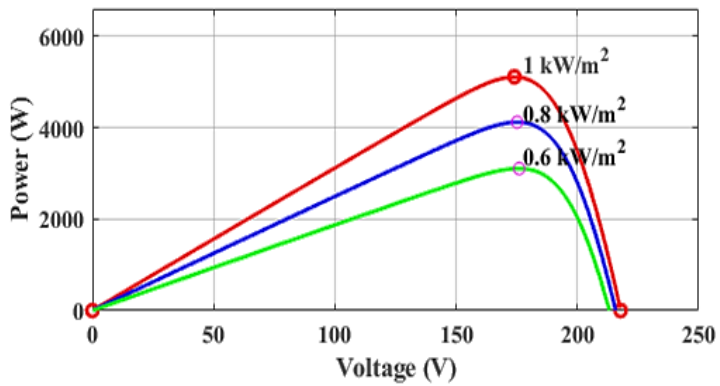

(b)

Figure 3. Photovoltaic (a) I-V characteristics (b) P-V characteristics

\subsection{DC/DC converter}

When a PV module is used in a system the operating point is decided by the connected load. The efficiency of the PV system can be improved if the PV module is operated at maximum power point irrespective of the varying atmospheric conditions. The MPPT mechanism depends on the basics of impedance matching between the PV array and the load, which is essential for maximum power transfer. A DC to DC converter is used to attain the MPP from the PV array [23].

Several types of DC-DC converter has been handled for PV system implementations in the literature. Some of them use boost converters which is used to step up the output voltage, buck converter for step down the output voltage and buck-boost, Cuk and single ended primary inductor converter (SEPIC) are used to either step up or step down [27-29,31-34].

DC-DC buck converter is used in the present study for interfacing loads that require low input voltage. It is the simplest types among of the converters and it has the lowest part count. The size of the inductor is smaller than the other which have the same output power, and this will make a buck converter more efficient. As Buck converter is stable, it can be operated at full range of duty cycle [35]. It is commonly used for storing energy from PV into the battery [36].

The circuit configuration of DC-DC buck converter is shown in Figure 4, it mainly consists of a diode, a switch, an inductor and a capacitor. By changing the duty cycle of the switch, the load impedance can be matched with source impedance to attain the maximum power from the PV panel. For continuouscurrent mode of operation, assuming a MOSFET switch, as the switch is on state for a time duration of $t_{\text {on }}$ the inductor current passes through the switch then the diode becomes reverse biased. A positive voltage will then appear across the inductor which causes a linear increase in the inductor current $i_{L}$. As the switch is turned off, $i_{L}$ continues to flow as a result of the inductive energy storage. This current will flow through the diode and decreases. The average output voltage can be calculated in terms of the switch duty ratio as [23]:

$$
\begin{aligned}
& V_{o}=\frac{T_{o n}}{T} V_{i n} \\
& D=\frac{T_{o n}}{T}
\end{aligned}
$$

where $V_{\text {in }}$ is the input to the converter from the PV, $V_{o}$ is the output of the converter delivered to the load, $T$ is the converter duty cycle and $T_{o n}$ is the on the MOSTEF on time.

For the buck converter, the value of the filter inductance that determines the boundary between Continuous conduction mode (CCM) and discontinuous conduction mode (DCM) is given by (6) [37]:

$$
L=\frac{(1-D) R}{2 f_{s}}
$$

where $R$ is the load resistance and $f_{s}$ is the switching frequency. 
For limiting the converter output voltage ripple lower than a certain value $V_{r}$, the output filter capacitance $C$ must be greater than $C_{\min }$ which can be given by the (7):

$$
C=\frac{(1-D) V_{o}}{8 V_{r} L f_{s}^{2}}
$$

If the PV output current ripple is taken less than $2 \%$ of its mean value, then the value of input capacitor can be calculated using (8) [38]:

$$
C_{i n} \geq \frac{\left(1-D_{c m}\right) I_{o m} D_{c m}}{0.02 I_{p v m} R_{p v m} f_{s}}
$$

where $D_{c m}$ is the converter duty cycle; $I_{o m}$ is the output current dc component; $I_{p v m}$ is the converter input current and $R_{p v m} i$ s the PV array internal resistance, when PV operate at MPP. $R_{p v m}$ is defined as

$$
R_{p v m}=\frac{V_{\text {inm }}}{I_{p v m}}
$$

Where $V_{\text {inm }}$ is the PV array output voltage at the maximum power point.

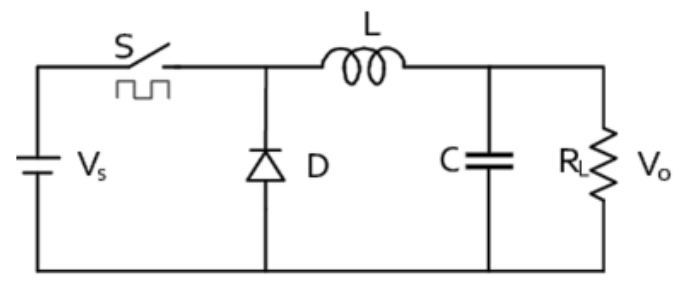

Figure 4. DC-DC buck converter main circuit

\subsection{Perturb and observe (P\&O) MPPT algorithm \\ 2.3.1. Conventional P\&O}

$\mathrm{P} \& \mathrm{O}$ algorithm is widely used in MPPT because of their simple structure and few required measurement parameters. The concept of the algorithm is to increase or decrease the PV array voltage, then the effect of this change on the PV generated power will be observed [39]. As a result, the controller will change the converter duty cycle using pulse width modulation to achieve maximum power transfer to the load. If the new computed power is greater than the old one, the controller keeps the same direction of the duty cycle and if the power falls, the controller reverses the direction of the duty cycle. A simple flow chart of the conventional $\mathrm{P} \& \mathrm{O}$ is shown in Figure 5.

The $\mathrm{P} \& \mathrm{O}$ shows tracking failure under rapid environmental condition changes as illustrated in Fig. 6 . Under the constant G1, the point MPP1 must move to B by a positive perturbation step $(+\Delta \mathrm{V})$, then it would return to MPP1 by a negative perturbation step $(-\Delta \mathrm{V})$ as a result of comparing powers between MPP1 and B. Suppose that the (P-V) characteristic is suddenly changed from G1 to G2 because of irradiation change. However, the MPP1 will move to D due to the changed P-V characteristic G2. In this case, the next perturbation must be negative for moving from $\mathrm{D}$ to $\mathrm{MPP} 2$ (as $\Delta \mathrm{P}_{\mathrm{pv}}>0$ ), but $\mathrm{D}$ will jump oppositely to $\mathrm{E}$ due to the positive perturbation $(+\Delta \mathrm{V})$.

The $\mathrm{P} \& \mathrm{O}$ controller orders the positive perturbation as the result that the power at $\mathrm{D}$ is still higher than the power at MPP1. This phenomenon disturbs the controller to track toward the new MPP immediately when the environmental condition is changed. This will result in successive power loss [26].

To overcome the drawbacks of the conventional $\mathrm{P} \& \mathrm{O}$ a modified $\mathrm{P} \& \mathrm{O}$ algorithm has been used for an accurate and faster MPPT during slow and sudden changes of irradiation. 


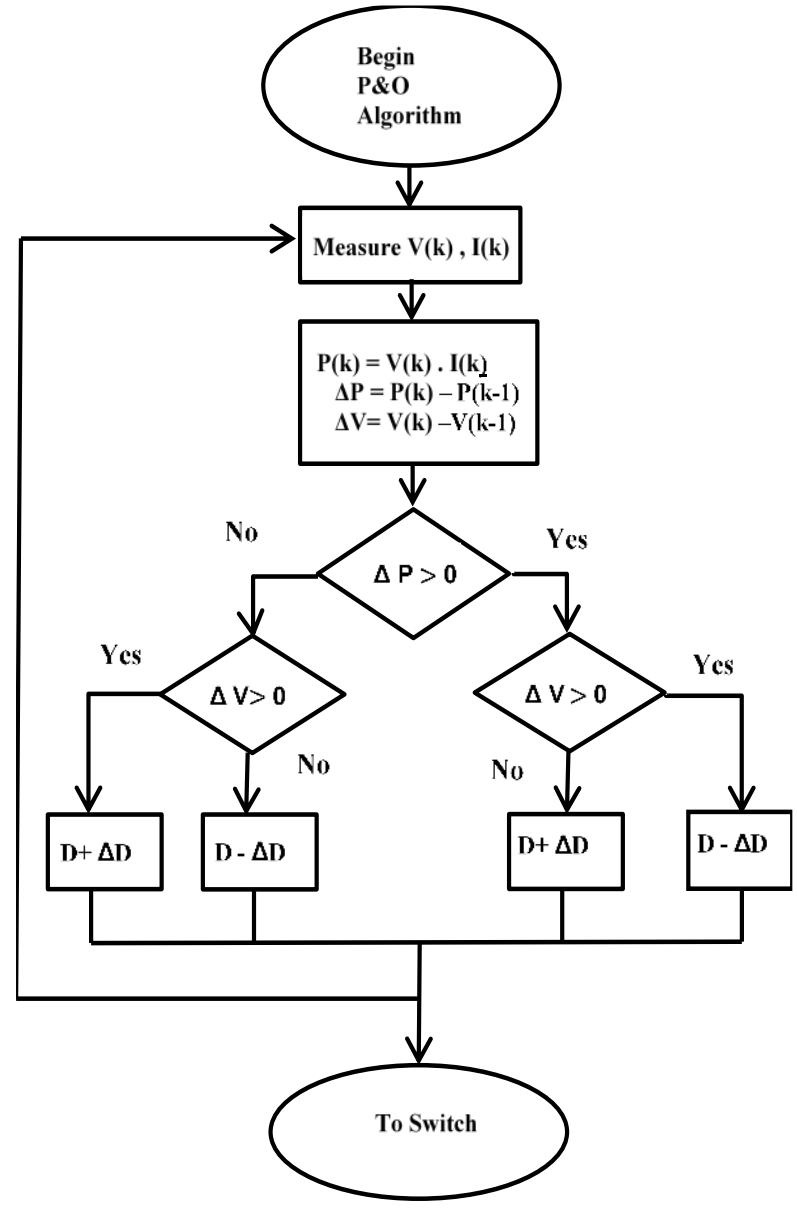

Figure 5. Conventional P\&O Flow Chart For MPPT PV System

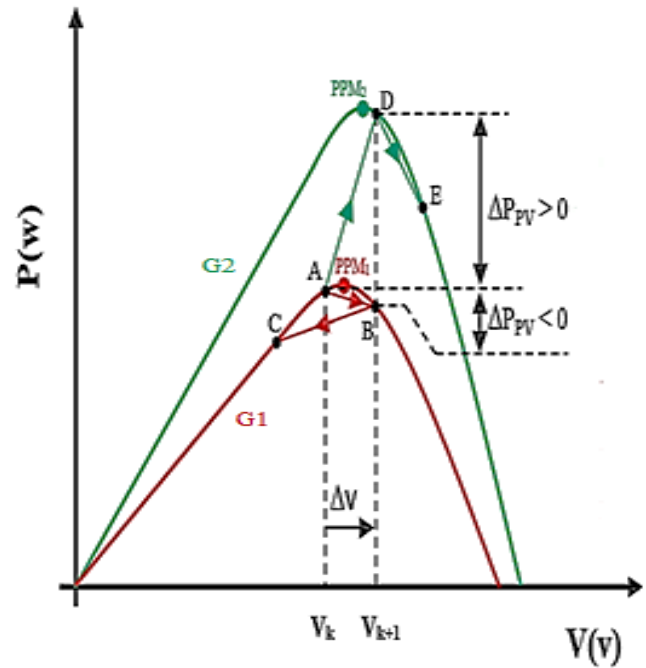

Figure 6. MPPT tracking loss under sudden irradiation change [26]

\subsubsection{Modified P\&O algorithm}

P\&O technique needs only two sensors to measure the PV output voltage and current and hence the $\mathrm{PV}$ power is calculated. The modified $\mathrm{P} \& \mathrm{O}$ algorithm differs from the conventional one by adding the variation in PV current as a third parameter in the flow chart. This new algorithm is capable of eliminating the MPPT deviation from the tracking way. The modified P\&O flow chart is shown in Figure 7. It is clear that there are eight cases of the operating point perturbation. Four cases are for the fixed irradiation and the remaining four cases are for the rapid change of irradiation level [27].

Table 1 presents the eight cases after the application of perturbation; the result of power difference gives either correct or the incorrect MPP tracking direction and the corresponding resulting control signal to the converter (duty cycle). For a fixed irradiation ( $\mathrm{G}$ is constant) on the PV array, an opposite sign change of voltage and current (cases 1,2,3 and 4) results from the algorithm. The other four cases (cases 5, 6, 7 and 8) are for the variable irradiation level ( $\mathrm{G}$ increases or decreases). The algorithm will run as the conventional\&O for fixed irradiation and as the irradiation level varied, the modified algorithm will work in reverse of the conventional one to attain the MPP.

For increasing the perturbation tracking speed, a double step is taken as the tracking is deviated from the MPP (Incorrect cases 2,4,6,8). This will enable the algorithm to distinguish whiter the change in power is resulting from the change irradiation or due to the perturbation in reference voltage, and hence avoiding MPPT deviation. 


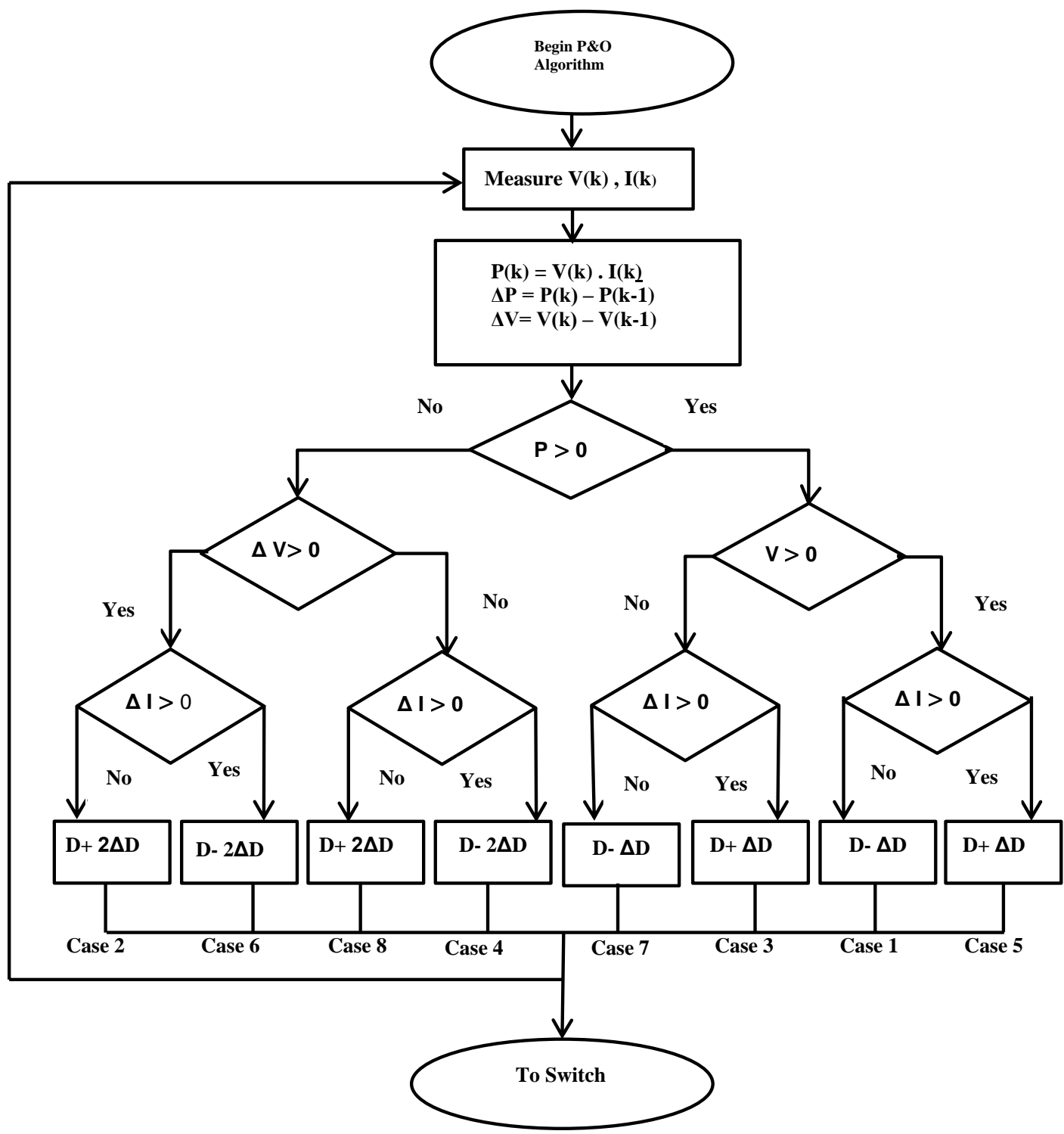

Figure 7. The modified $\mathrm{P} \& \mathrm{O}$ flow chart

Table 1. The different control action for the modified P\&O algorithm

\begin{tabular}{ccccccc}
\hline Case & $\Delta \mathrm{V}$ & $\Delta \mathrm{I}$ & $\Delta \mathrm{P}$ & $\mathrm{G}$ & Tracking action & Duty control action \\
\hline 1 & + & - & + & Constant & Correct & $\mathrm{D}=\mathrm{D}-\Delta \mathrm{D}$ \\
2 & + & - & - & Constant & Incorrect & $\mathrm{D}=\mathrm{D}+2 \Delta \mathrm{D}$ \\
3 & - & + & + & Constant & Correct & $\mathrm{D}=\mathrm{D}+\Delta \mathrm{D}$ \\
4 & - & + & - & Constant & Incorrect & $\mathrm{D}=\mathrm{D}-2 \Delta \mathrm{D}$ \\
5 & + & + & + & Increase & Correct & $\mathrm{D}=\mathrm{D}+\Delta \mathrm{D}$ \\
6 & + & + & - & Increase & Incorrect & $\mathrm{D}=\mathrm{D}-2 \Delta \mathrm{D}$ \\
7 & - & - & + & Decrease & Correct & $\mathrm{D}=\mathrm{D}-\Delta \mathrm{D}$ \\
8 & - & - & - & Decrease & Incorrect & $\mathrm{D}=\mathrm{D}-2 \mathrm{D}$ \\
\hline
\end{tabular}

\section{SMULATION AND DISCUSSION}

The P\&O algorithm for both conventional and modified technique is tested using the PV system with PV panel (1Soltech 1STH-215-P). The model is implemented using Matlab/Simulink(2018b) package. The parameters of the PV panel that has been used in this work are illustrated in Table 2. The array consists of 4 parallel panel and 6 series panels. PVarray, I-V and P-V characteristics had been shown in figure 3.

The PV array is connected to a buck converter through an input capacitor $\mathrm{C}_{\text {in }}$ of $(0.8 \mathrm{~F})$. The converter inductor and output capacitor values are selected to be $(162 \mu \mathrm{H})$ and $(5 \mathrm{~F})$ respectively, assuming that the switching frequency is $(1 \mathrm{kHz})$ and the output voltage ripple is $(5 \mathrm{mV})$. 
Table 2. PV panel parameters model 1Soltech 1STH-215-P

\begin{tabular}{lc}
\hline Parameters & Value \\
\hline Maximum Power(W) & 213.15 \\
Open circuit voltage $\mathrm{V}_{\mathrm{OC}}(\mathrm{V})$ & 36.3 \\
Short circuit current Isc $(\mathrm{A})$ & 7.84 \\
Voltage at maximum power point Vmp(V) & 29 \\
Current at maximum power point Imp(A) & 7.35 \\
Temperature coefficient of Voc $(\% /$ deg.C) & -0.36099 \\
Temperature coefficient of of Isc(\%/deg.C) & 0.102 \\
Diode saturation current Id(A) & 0.98117 \\
Shunt resistance $\operatorname{Rsh}(\Omega)$ & 313.3991 \\
Series resistance $\operatorname{Rs}(\Omega)$ & 0.39383 \\
\hline
\end{tabular}

\subsection{Conventional P\&O algorithm Performance under standard test conditions (STC)}

The PV array is tested under STC $\left(\mathrm{G}=1000 \mathrm{~W} / \mathrm{m}^{2}, \mathrm{~T}=25^{\circ} \mathrm{C}\right)$ with conventional P\&O MPPT controller having a fixed step size $(\Delta \mathrm{D})$ of $1 \times 10^{-5} S$. The control signal is applied to the buck converter to maximize the output power from the PV array. Figure 8 presents the simulation of the array output voltage, current, power and duty cycle of the converter. At steady state (time $=17.5 \mathrm{~s}$ ), and after comparison with I-V and $\mathrm{P}-\mathrm{V}$ characteristics of the PV array shown in figure 3 the simulation results show that the algorithm has a good tracking for the maximum power point of the PV array $\left(\mathrm{I}_{\mathrm{MPP}} \cong 29 \mathrm{~A}, \mathrm{~V}_{\mathrm{MPP}} \cong 174\right.$ and $\left.\mathrm{P}_{\mathrm{MPP}} \cong 5100 \mathrm{~W}\right)$.

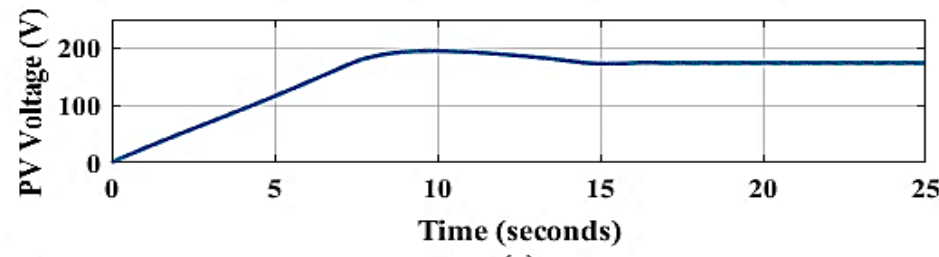

(a)
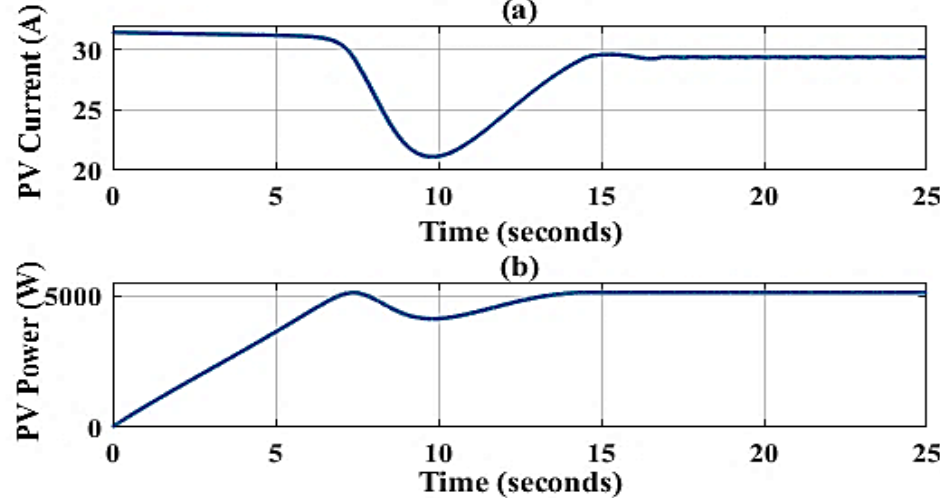

(c)

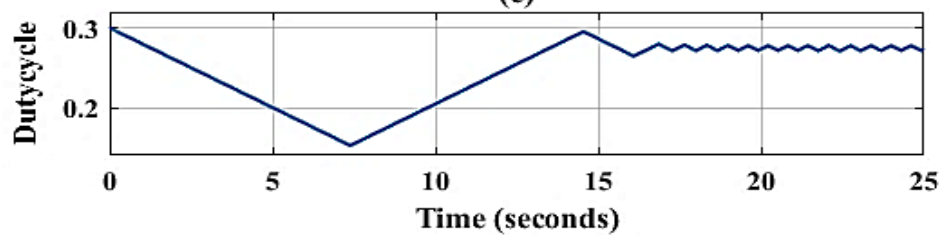

(d)

Figure 8 Conventional $\mathrm{P} \& \mathrm{O}$ algorithm performance MPPT under $\mathrm{STC}\left(\mathrm{G}=1000 \mathrm{~W} / \mathrm{m}^{2}, \mathrm{~T}=25^{\circ} \mathrm{C}\right)$.

PV array (a) voltage (b) current (c) power and (d) Converter duty cycle

\subsection{Modified P\&O algorithm Performance under variable irradiation level}

To verify the performance of the modified P\&O MPPT algorithm under variable irradiation level, an arbitrary irradiation level profile is used as an input to the PV array as shown in Figure 9.

Both conventional and modified P\&O MPPT algorithms have been simulated and compared with the ideal MPP of the PV array under slow and rapid irradiation level change. This comparison is illustrated in Figure 10. By applying irradiation level profile with $600 \mathrm{~W} / \mathrm{m}^{2}$ (from 0 to $30 \mathrm{~s}$ ) the simulation has proved that the modified $\mathrm{P} \& \mathrm{O}$ is faster to attain the steady state than the conventional algorithm (17s v's $23 \mathrm{~s}$ ). The 
oscillation for the modified P\&O is less than the conventional and hence the power loss is lower for the modified $\mathrm{P} \& \mathrm{O}$.

For slow irradiation level change (ramp up $600 \mathrm{~W} / \mathrm{m}^{2}$ to $1000 \mathrm{~W} / \mathrm{m}^{2}$ which is applied between time 30s-35 s and ramp down $1000 \mathrm{~W} / \mathrm{m}^{2}-800 \mathrm{~W} / \mathrm{m}^{2}$ applied between time $40 \mathrm{~s}-45 \mathrm{~s}$ ), the modified $\mathrm{P} \& \mathrm{O}$ shows less diverge from the ideal MPP. As the irradiation level changes rapidly $\left(800 \mathrm{~W} / \mathrm{m}^{2}\right.$ to $200 \mathrm{~W} / \mathrm{m}^{2}$ at time $50 \mathrm{~s})$, it's clear that the modified algorithm attains the steady state faster than the conventional P\&O (65s v's 78 s) and this will also decrease the power loss as the modified algorithm is used.

Figure 12 illustrates the difference between the modified and conventional P\&O efficiency. The simulated figure shows that the oscillation for the modified algorithm is less than the conventional and the power loss is less. The average efficiency of the modified $\mathrm{P} \& \mathrm{O}$ is greater than the conventional by $4.34 \%$.

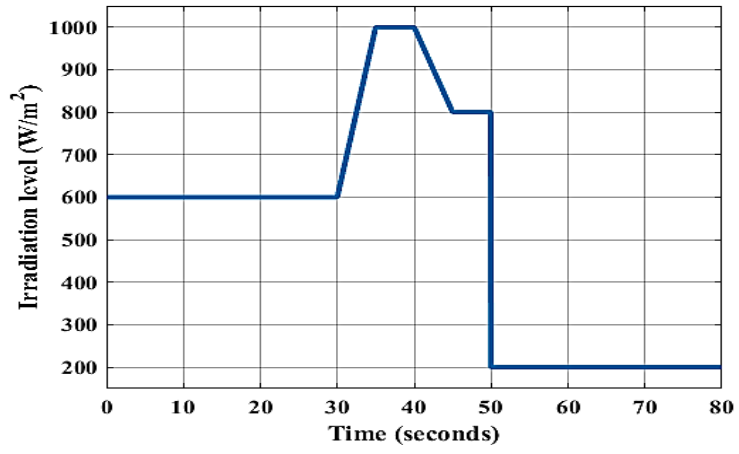

Figure 9. Irradiation level variation profile

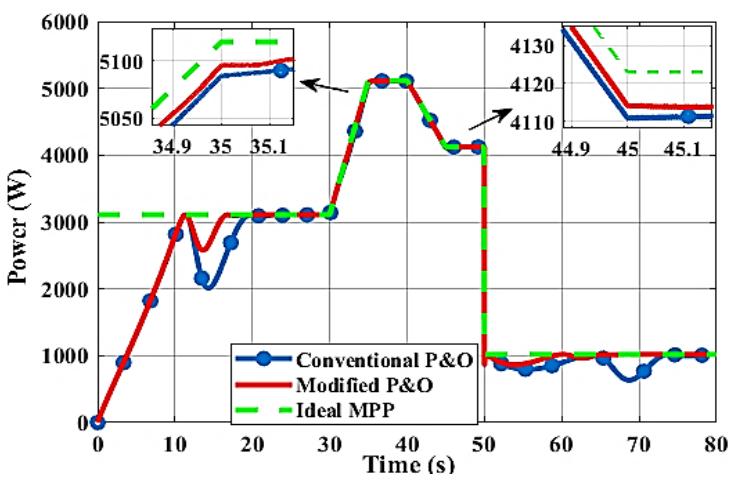

Figure 10. MPPT of Modified and conventional $\mathrm{P} \& \mathrm{O}$ as compared with ideal MPP

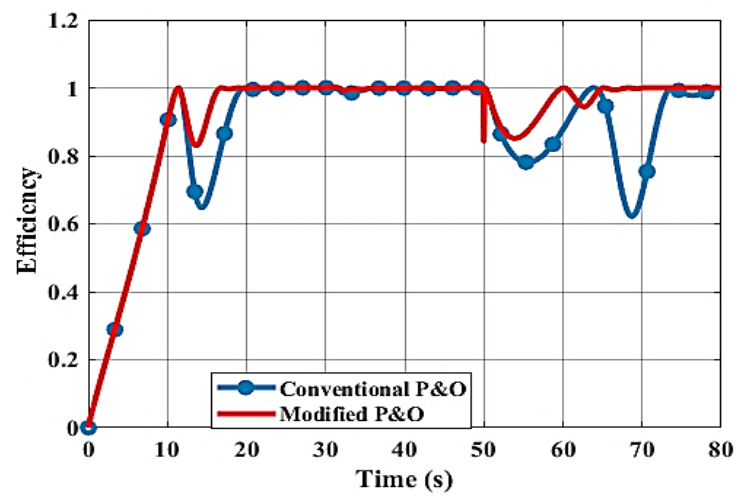

Figure 11. MPPT comparisons for modified and conventional P\&O algorithm

\section{CONCLUSIONS}

Global interest has become very great with the use of solar energy systems as a source of clean electric energy. One of the main problems that solar energy systems suffer from being the change in the power production of the solar panels as a result of changing weather conditions such as solar irradiation that may result from the presence of shadows caused by neighboring buildings or clouds... etc. The change in the production power caused by the presence of shadows is a rapid change. Therefore, solar energy systems operating in these conditions need to have a smart tracking algorithm for the maximum power point that solar cells generate at every moment. The $\mathrm{P} \& \mathrm{O}$ tracking algorithm is considered a simple way to track the maximum power point, which depends on perturbating the voltage of the solar panels to track the PV maximum power point, but this method suffers from oscillation around the MPP during steady state and diverge from maximum point when rapid change of environmental conditions occurs. Therefore, in this paper a modified $\mathrm{P} \& \mathrm{O}$ algorithm has been used by adding another parameter which depends on measuring the amount of change in current in addition to the voltages to find the maximum power point. The algorithm has been used to control the duty cycle of a DC-DC buck converter to maximize the power output from the PV. 
The simulation shows that during constant irradiation $\left(600 \mathrm{~W} / \mathrm{m}^{2}\right)$ the modified $\mathrm{P} \& \mathrm{O}$ algorithm has the ability to attain the steady state faster than the conventional one. As the irradiation level changes rapidly from 800 to $200 \mathrm{~W} / \mathrm{m}^{2}$, the modified algorithm attains the steady state faster than the conventional P\&O. The power loss due to oscillation is less for modified P\&O. For slow irradiation level change (ramp up 600 to 1000 and ramp down 1000-800) $\mathrm{W} / \mathrm{m}^{2}$, the modified P\&O shows less diverge from the MPP. The average efficiency of the modified $\mathrm{P} \& \mathrm{O}$ is greater than the conventional one by $4.34 \%$.

\section{REFERENCES}

[1] Mohd Rizwan Sirajuddin Shaikh, Santosh B. Waghmare, Suvarna Shankar Labade, Pooja Vittal Fuke, Anil Tekale, "A Review Paper on Electricity Generation from Solar Energy," International Journal for Research in Applied Science \& Engineering Technology (IJRASET), Vol. 5, No. 9, pp. 1884-1889, September 2017.

[2] Muhammad Ammirrul Atiqi Mohd Zainuri, Mohd Amran Mohd Radzi, Azura Che Soh, Nasrudin Abd Rahim, "Development of adaptive perturb and observe-fuzzy control maximum power point tracking for photovoltaic boost dc-dc converter," IET Renew. Power Gener., Vol. 8, No. 2, pp. 183-194, 2014.

[3] B. Pakkiraiah, G. Durga Sukumar, "Research Survey on Various MPPT Performance Issues to Improve the Solar PV System Efficiency,” Journal of Solar Energy, Vol. 2016.

[4] Milad Samady Should, "Comparison of Maximum Power Point Tracking (MPPT) Algorithms to Control DC-DC Converters in Photovoltaic Systems," Recent Advances in Electrical \& Electronic Engineering, Vol.12, No. 4, 2019.

[5] Mojtaba Kordestani, Alireza Mize, Ali Akbar Safavi, Mehrdad Saif, Senio., "Maximum Power Point Tracker (MPPT) for Photovoltaic Power Systems-A Systematic Literature Review," European Control Conference (ECC), June 12-15, Limassol, Cyprus ,2018.

[6] Amit Kumer Podder, Naruttam Kumar Roy, Hemanshu Roy Pota, "MPPT methods for solar PV systems: a critical review based on tracking nature," IET Renewable Power Generation, Review Article, Vol.13, No.10, pp. $1615-1632,2019$.

[7] Jawad Chorfi, Malika Zazi, Mohamed Mansori "A New Intelligent MPPT Based on ANN Algorithm for Photovoltaic System, “IEEE, 6th International Renewable and Sustainable Energy Conference (IRSEC), 2018.

[8] Rozana Alik, Awang Jusoh, Tole Sutikno "A Review on Perturb and Observe Maximum Power Point Tracking in Photovoltaic System” TELKOMNIKA Telecommunication, Computing, Electronics and Control, Vol 13, No 3, pp. 745-751, September 2015.

[9] Priyatosh Jena, Rajen Pudur, Prakash Kumar Ray, Asit Mohanty "ANN Based MPPT Applied to Solar Powered Water Pumping System Using BLDC Motor," IEEE International Conference on Sustainable Energy Technologies and Systems (ICSETS) 26 Feb.-1 March 2019, DOI: 10.1109/ICSETS.2019.8744804.

[10] M. Bechouat, M. Sedraoui, C. -E. Feraga, M. Aioud and S. Kahla, "Modeling and Fuzzy MPPT Controller Design for Photovoltaic Module Equipped with a Closed-Loop Cooling System," Journal of Electronic Maerials, Vol. 48, No. 9, 2019.

[11] Abhishek Roshan, Prakash Dwivedi and Himesh Kumar, "Fuzzy Based MPPT and Energy Management Strategy," IEEE 10th Control and System Graduate Research Colloquium (ICSGRC 2019), 2 - 3 August 2019, Shah Alam, Malaysia.

[12] Mohamed M. Refaat, Yousry Atia, M.M. Sayed, Hossam A. Abdel Fattah, "Maximum power point tracking of photovoltaic system using adaptive fuzzy controller," Intl Conf on Advanced Control Circuits Systems (ACCS) Systems \& 2017 Intl Conf on New Paradigms in Electronics \& Information Technology (PEIT) 5-8 Nov. 2017, Alexandria, Egypt.

[13] Salmi Hassan, Badri Abdelmajid, Zegrari Mourad, Sahel Aicha, Baghdad Abdenaceur," An Advanced MPPT Based on Artificial Bee Colony Algorithm for MPPT Photovoltaic System under Partial Shading Condition," International Journal of Power Electronics and Drive System (IJPEDS) Vol. 8, No. 2, pp. 647 653, June 2017.

[14] Hassan Salmi, Abdelmajid Badri, Mourad Zegrari, "Maximum Power Point Tracking (MPPT) Using Artificial Bee Colony Based Algorithm for Photovoltaic System," International Journal of Intelligent Information Systems, Vol. 5, No. 1, pp. 1-4, 2016.

[15] Guiza Dhaouadi, Ounnas Djamel, Soufi Youcef, Chenikhe Salah,” Implementation of Incremental Conductance Based MPPT Algorithm for Photovoltaic System," The 4th International Conference on Power Electronics and their Applications (ICPEA), 25-27 September 2019, Elazig, Turkey.

[16] Parween R. Kareem, "Simulation of the Incremental Conductance Algorithm for Maximum Power Point Tracking Of Photovoltaic System Based on Matlab,” Journal of Engineering Sciences, Vol.12, No. 01, pp. 34-43.,2019.

[17] Bahaa Abdulkhaliq N., A. L. Mahmood, "Power Load Optimization for a remote area BTS Site Using MPPT Algorithm, "Journal of Information Science and Computing Technology, Vol.4, No.2, pp318-325, 2015.

[18] Md. Masud Rana, Md. Rayhan Ali, Abul Kalam Ajad, Md. Moznuzzaman, "Analysis of P\&O and INC MPPT Techniques for PV Array Using MATLAB," IOSR Journal of Electrical and Electronics Engineering (IOSRJEEE), Vol. 11, No.4 Ver. II (Jul. - Aug. 2016), PP 80-86.

[19] Khadidja Saidi, Mountassar Maamoun, M'hamed Bounekhla, "A new high performance variable step size perturb-and-observe MPPT algorithm for photovoltaic system," International Journal of Power Electronics and Drive System (IJPEDS), Vol. 10, No. 3, pp. 1662 1674, Sep 2019. 
[20] Fangrui Liu, Yong Kang, Yu Zhang and Shanxu Duan, "Comparison of P\&O and Hill Climbing MPPT Methods for Grid-Connected PV Converter," 2008 3rd IEEE Conference on Industrial Electronics and Applications, 3-5 June, Singapore, 2008.

[21] Rozana Alik, Awang Jusoh, Tole Sutikno," A Review on Perturb and Observe Maximum Power Point Tracking in Photovoltaic System," TELKOMNIKA (Telecommunication, Computing, Electronics and Control), Vol.13, No.3, pp. 745 751, September 2015.

[22] Osisioma Ezinwannea, Fu Zhongwena, Li Zhijunb, "Energy Performance and Cost Comparison of MPPT Techniques for Photovoltaics and other Applications," 3rd International Conference on Energy and Environment Research, ICEER 2016, 7-11 September 2016, Barcelona, Spain.

[23] K. Muthukumar, T.S. Anandhi., "Real Time Implementation of Variable Step Size Based P\&O MPPT for PV Systems Based on dSPACE," International Journal of Power Electronics and Drive System (IJPEDS), Vol. 7, No. 3, pp. 915 925, September 2016.

[24] Nabil Kahoul., Mounira Mekki, "Adaptive P\&O MPPT Technique for Photovoltaic Buck-Boost Converter System,” International Journal of Computer Applications, Vol. 112, No 12, pp. 23-27, February 2015.

[25] Khaled Bataineh, Yazan Taamneh., "Adaptive Neuro-fuzzy Inference System-based Improvement of Perturb and observe Maximum Power Point Tracking Method for Photovoltaic System," International Journal of Power Electronics and Drive System (IJPEDS) Vol. 8, No. 3, September 2017, pp. 1327 1334.

[26] M. F. Almi, H. Belmili, M. Arrouf and B. Bendib., "A Novel Adaptive Variable Step Size P\&O MPPT Algorithm," Academic Journal of Science, 06(01):533-540 (2016).

[27] Abdelhakim Belkai, Ilhami Colak, Korhan Kayisli., "Implementation of a modified P\&O-MPPT algorithm adapted for varying solar radiation conditions," Electrical Engineering, Vol. 99, No. 3, pp. 839-846. 2017.

[28] H. Mohssine, M. Kourchi, H. Bouhouch F. Debbagh," Perturb and Observe (P\&O) and Incremental Conductance (INC) MPPT Algorithms for PV Panels," International Journal of Soft Computing and Engineering (IJSCE), Volume-5 Issue-2, May 2015.

[29] Gaurav Yadav, Kiran Kumar Jaladi, "Comparison of different parameters using Single Diode and Double Diode model of PV module in a PV-Battery system using MATLAB Simulink," 4th IEEE India Council International Conference (INDICON), Dec,2017.

[30] Haidar Islam, et al, "Performance Evaluation of Maximum Power Point Tracking Approaches and Photovoltaic Systems," Energies, Vol. 11, 365, 2018.

[31] Obaidullah Lodin, Inderpreet Kaur, Harpreet Kaur, "Predictive-P\&O Mppt Algorithm for Fast and Reliable Tracking of Maximum Power Point in Solar Energy Systems," International Journal of Recent Technology and Engineering (IJRTE), Vol. 7, Issue-6S4, pp. 264- 268, April 2019.

[32] Anooja Shahul, Reenu George, Emmaneul Babu., "Comparison between Conventional P \& O and Drift Free P \& O MPPT Algorithm for PV System," International Journal of Advanced Research in Electrical, Electronics and Instrumentation Engineering, Vol. 6, Issue 3, pp. 1081-1086, March 2017.

[33] Ahmed M. Atallah, Almoataz Y. Abdelaziz, and Raihan S. Jumaah, "Implementation of Perturb and Observe MPPT Of PV System with Direct Control Method Using Buck and Buck Boost Converter," Emerging Trends in Electrical, Electronics \& Instrumentation Engineering: An International Journal (EEIEJ), Vol. 1, No. 1, pp. 3144, 2014.

[34] Srushti R. Chafle, Uttam B. Vaidya, Z. J. Khan, "Design of Cuk Converter with MPPT Technique," International Journal of Innovative Research in Electrical, Electronic, Instrumentation and control engineering, Vol. 1, No. 4, pp. 161-167, July 2013.

[35] Ramsha Iftikhar, et al, "MPPT for Photovoltaic System Using Nonlinear Controller," International Journal of Photoenergy, 2018.

[36] Ronnakorn Khambuyaa, Sudarat Khwan-ona," A New High Step-Down DC-DC Converter for Renewable Energy System Applications," International Electrical Engineering Congress, IEECON2016, 2-4 March 2016, Chiang Mai, Thailand.

[37] Muhammad H. Rashid, "Power Electronics Handbook", Academic Press, 2001.

[38] Eftichios Koutroulis, Kostas Kalaitzakis, Nicholas C. Voulgaris, "Development of a Microcontroller-Based Photovoltaic Maximum Power Point Tracking Control System," IEEE Transactions on Power Electronics, Vol. 16, No. 1, pp, 46-54, Jan, 2001.

[39] Oumnia Lagdani, Mourad Trihi, Badre Bossoufi, "PV array connected to the grid with the implementation of MPPT algorithms (INC, P\&O and FL method)," International Journal of Power Electronics and Drive System (IJPEDS) Vol. 10, No. 4, pp. 2084-2095, December 2019. 


\section{BIOGRAPHIES OF AUTHORS}
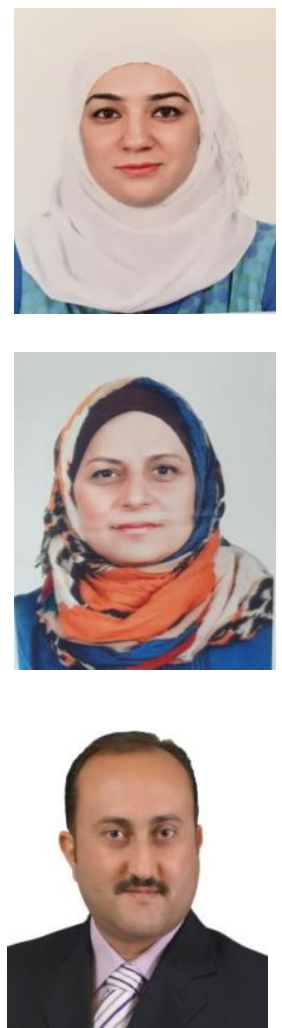

Bahaa Abdulkhaliq Numan is an assistant lecturer in college of engineering, electronics and communications department, Al-Nahrain University, she got her BSc. Degree in electronic engineering from Diyala university, Iraq 2005, MSc. Degree in electronic and communications engineering from Al-Nahrain University, Iraq, 2016. Her main interest in the electronic and communications field, power electronics and renewable energy.

Amina M. Shakir received the B.Sc. Degree in Electrical Engineering from the University of Technology/Baghdad, Iraq in 1990, her M.Sc. In power and machine engineering from the University of Technology/Baghdad, Iraq in 1998, her Ph.D. in power system and machine from Baghdad university in 2007, she is now a lecturer at Al Nahrain University / Electronic and the communications Engineering Department. Her interest researches include photovoltaic modeling and control, energy conversion from renewable sources and power electronics. (aminaalkafajiam@gmail.com).

Anas Lateef Mahmood received his B.Sc., M.Sc., and Ph.D. in Electronic and Communications Engineering / Electronic Circuits and Systems from Al-Nahrain University college of engineering in 1999, 2002, and 2007 respectively. He is currently the head of Electronic and Communications Department. His research interest includes power electronics and renewable energy. 